\title{
Use of molecular markers in reciprocal recurrent selection of maize increases heterosis effects
}

\author{
A.P.C.G. Berilli, M.G. Pereira, L.S.A. Gonçalves, K.S. da Cunha, \\ H.C.C. Ramos, G.A. Souza Filho and A.T. do Amaral Júnior \\ Universidade Estadual do Norte Fluminense Darcy Ribeiro, \\ Campos dos Goytacazes, RJ, Brasil \\ Corresponding author: M.G. Pereira \\ E-mail: messias@uenf.br
}

Genet. Mol. Res. 10 (4): 2589-2596 (2011)

Received December 22, 2010

Accepted July 10, 2011

Published October 25, 2011

DOI http://dx.doi.org/10.4238/2011.October.25.6

\begin{abstract}
We examined the effect of incorporation of molecular markers on variability between and within populations in order to maximize heterotic effects and longevity of a maize reciprocal recurrent selection program. Molecular variability was quantified by inter-simple sequence repeat (ISSR) markers between and within the maize populations Cimmyt and Piranão in the 10th cycle of a reciprocal recurrent selection program. Forty-two $\mathrm{S}_{1}$ progenies of each population were analyzed, these being families of full-sibs selected according to their agronomic traits. Thirteen primers were selected, which produced 140 bands; 114 of them were polymorphic and 26 monomorphic. Based on UPGMA grouping analysis and by genetic distances, it was possible to identify "contaminant" progenies. These progenies belong to the Piranão or Cimmyt groups, but cluster in the opposite heterotic group. Identification of "contaminant" progenies is relevant for selection, because, besides identifying genotypes that should be eliminated at the recombination stage, it allows increased heterosis expression in crosses between more genetically distinct individuals. After the elimination of the "contaminant" progenies and those that were allocated between the heterotic groups, a new statistical analysis was carried out, which demonstrated increased genetic distances
\end{abstract}


between the populations. It was concluded that the application of molecular markers in reciprocal recurrent selection programs allows the optimization of the monitoring of genetic variability within and between populations, favoring recombination between more distant progenies, besides ensuring increased longevity of the reciprocal recurrent selection program.

Key words: Zea mays L.; ISSR; Plant breeding

\section{INTRODUCTION}

Information about the relationship between genotypes or groups of genotypes or populations is vital for plant breeding programs to identify genetically distant parental combinations that can be used to produce superior segregant hybrids. It is also important to evaluate the degree of germplasm genetic erosion and determine the magnitude of the genetic base (Mohammadi and Prasanna, 2003; Reif et al., 2005; Gonçalves et al., 2008; Leal et al., 2010). Quantification of relationships between genotypes using molecular information has become increasingly common in plant breeding programs. Molecular markers are stable and detectable in all tissues, regardless of the growth, differentiation, development, or stage of the cell. They are not subject to environmental, pleiotropic or epistatic effects (Agarwal et al., 2008; Collard and Mackill, 2008; Moose and Mumm, 2008). Research using molecular markers in maize has provided important information about genetic diversity before and after domestication of its wild teosinte ancestor of landraces and of elite germplasm (Buckler et al., 2006; Moose and Mumm, 2008).

The Universidade Estadual do Norte Fluminense Darcy Ribeiro (UENF) has been developing a breeding program aiming at improving agronomic characteristics of economic interest of the populations Cimmyt and Piranão using reciprocal recurrent selection.

Reciprocal recurrent selection, proposed by Comstock and Robinson (1948), aims at the simultaneous improvement of two populations. These populations, on their turn, must be genetically distant and present high agronomic potential. Reciprocal recurrent selection has some advantages, such as utilization of the expression of the additive effects by means of concentration of favorable alleles, from both populations; it also uses dominance deviations in recombination units, since the genetic distances are preserved between the populations, thus allowing heterosis exploration by crossing between lineages from the corresponding selected families (Hallauer and Miranda Filho, 1988; Lima Neto and Souza Júnior, 2009).

Molecular markers have been considered an important tool to help reciprocal recurrent selection, allowing monitoring of the genetic variability of the original and selected populations, identification of contaminants and selection of families to be recombined to maximize heterosis between populations (Pinto et al., 2003a,b; Tardin et al., 2007).

We genotyped $\mathrm{S}_{1}$ progenies, of the respective families of full siblings selected for agronomic characteristics of the populations Cimmyt and Piranão of the UENF reciprocal recurrent selection program, with the following objectives: i) identify the "contaminant" progenies, these being those whose identity may allow the grouping into a heterotic group different from the population from which it came; ii) assess the possibility of identifying the presence of little contrasting individuals between the groups, which are, therefore, of little interest for the recombination lot; iii) optimize heterotic effects in crosses between distant individuals, and iv) include longevity in the recurring selection program. 


\section{MATERIAL AND METHODS}

\section{Plant material and DNA extraction}

Eighty-four $\mathrm{S}_{1}$ progenies of the populations Cimmyt (1 to 42 ) and Piranão (43 to 84 ) were analyzed at the 10th cycle of reciprocal recurrent selection. They came from 84 plants (42 of each population) and formed the 42 families of full siblings selected according to their agronomic characteristics (Figure 1).

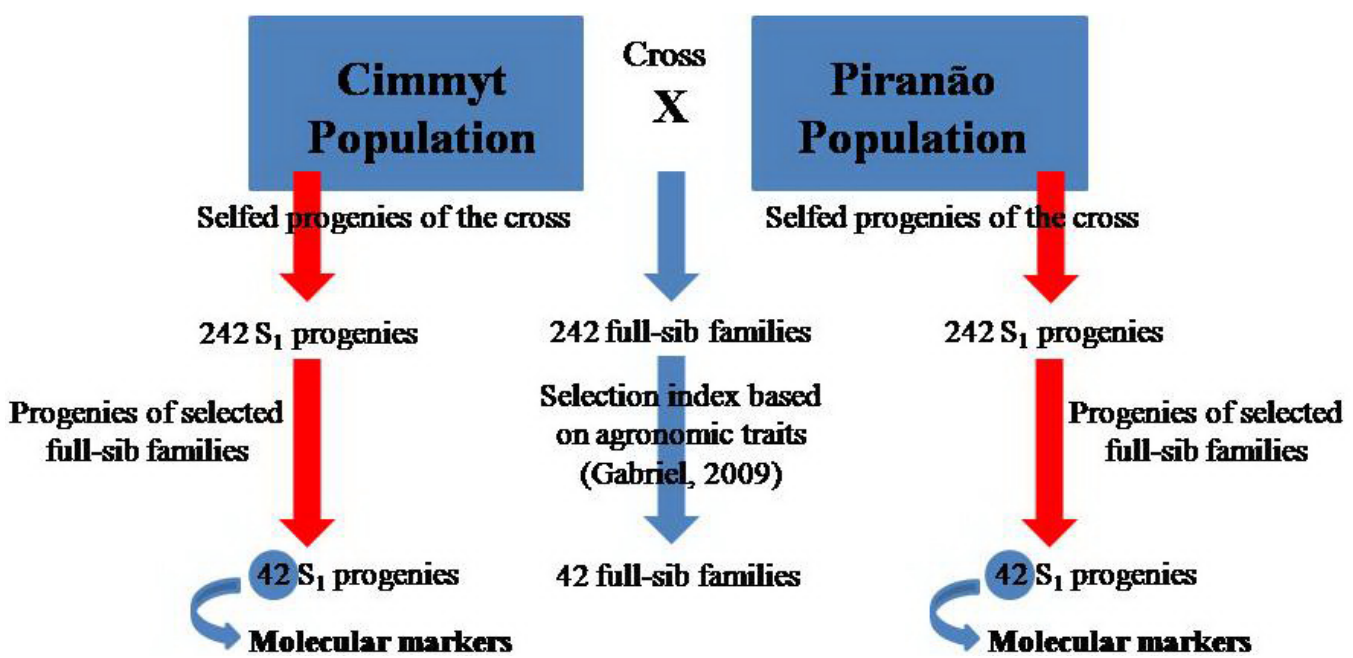

Figure 1. Scheme of selection of $S_{1}$ progenies at the 10th cycle of reciprocal recurrent selection of the maize populations Cimmyt and Piranão.

Total cellular DNA was extracted according to Doyle and Doyle (1990), with modifications suggested by Daher et al. (2002). The DNA was quantified on 1.0\% agarose gels, using the marker High DNA Mass Ladder (Invitrogen, USA). The gel was stained with a 1:1 mixture of 6 X Blue Juice $(0.4 \mathrm{~mL} 0.5 \mathrm{M}$ 10X TAE; $0.2 \mathrm{~mL} \mathrm{10 \%} \mathrm{SDS;} 0.2 \mathrm{~mL}$ bromophenol blue; 7.0 $\mathrm{mL}$ glycerol; $1.7 \mathrm{~mL}$ sterile water) and $5 \mathrm{X}$ GelRed $(1 \mu \mathrm{L} \mathrm{10,000X} \mathrm{GelRed} \mathrm{in} 0.5 \mathrm{~mL}$ DMSO; $2 \mathrm{~mL}$ ultrapure water). The image was revealed in a MiniBis Pro photo documentation system.

\section{Inter-simple sequence repeat (ISSR) amplification}

Primers were selected to produce ISSR fragments (Table 1) and the amplification reactions were carried out with the protocol of Williams et al. (1990), in a final volume of 20 $\mu \mathrm{L}$. Each reaction contained: $2 \mu \mathrm{L} 10 \mathrm{X}$ buffer $(500 \mathrm{mM} \mathrm{KCl}, 100 \mathrm{mM}$ Tris-HCL, $\mathrm{pH} 8.4), 2$ $\mu \mathrm{L} 25 \mathrm{mM} \mathrm{MgCl}_{2}, 1.6 \mu \mathrm{L} 2 \mathrm{mM}$ dNTPs, $1 \mu \mathrm{L}$ DMSO, $1.8 \mu \mathrm{L} 0.5 \mathrm{mM}$ primer, $5 \mathrm{U}$ Taq DNA polymerase, and $5 \mathrm{ng}$ genomic DNA. The final volume was completed with ultrapure water. The PCRs for the marker were conducted as follows: 4 min at $94^{\circ} \mathrm{C}$, followed by 37 cycles $\left[94^{\circ} \mathrm{C}\right.$ for $1 \mathrm{~min}$, at $46^{\circ}$ to $50^{\circ} \mathrm{C}$ for $2 \mathrm{~min}$ (depending on the primer used) and $72^{\circ} \mathrm{C}$ for $2 \mathrm{~min}$ ], and a final extension at $72^{\circ} \mathrm{C}$ for $7 \mathrm{~min}$. 


\begin{tabular}{|c|c|c|c|c|}
\hline \multirow[t]{2}{*}{ Primers } & \multirow[t]{2}{*}{ AT $\left({ }^{\circ} \mathrm{C}\right)$} & \multicolumn{2}{|c|}{ Bands } & \multirow[t]{2}{*}{ Size } \\
\hline & & Polymorphic & Monomorphic & \\
\hline$(\mathrm{GA})_{8} \mathrm{YC}$ & 50 & 8 & 2 & $280-900$ \\
\hline $\mathrm{GC}(\mathrm{GA})_{8}$ & 50 & 11 & 1 & $400-1100$ \\
\hline$(\mathrm{AG})_{8} \mathrm{YC}^{8}$ & 50 & 9 & 1 & $350-950$ \\
\hline$(\mathrm{CT})_{8}^{8} \mathrm{RC}$ & 45 & 14 & 1 & $280-2100$ \\
\hline$(\mathrm{CT})_{8}^{8} \mathrm{TG}$ & 45 & 11 & 1 & $350-850$ \\
\hline$(\mathrm{AGC})_{5} \mathrm{GR}$ & 47 & 10 & 3 & $200-700$ \\
\hline$(\mathrm{AGC})_{5}^{5} \mathrm{AY}$ & 50 & 9 & 2 & $300-750$ \\
\hline$(\mathrm{GAA})_{6}^{3}$ & 50 & 8 & 3 & $300-1300$ \\
\hline$(\mathrm{GTG})_{5} \mathrm{RG}$ & 55 & 9 & 2 & $150-800$ \\
\hline$(\mathrm{GCT})_{5}^{3} \mathrm{Y}$ & 55 & 9 & 2 & $250-1100$ \\
\hline$(\mathrm{CTC})_{5} \mathrm{RC}$ & 50 & 6 & 3 & $350-1100$ \\
\hline$(\mathrm{CAGA})_{4}$ & 45 & 6 & 1 & $400-1000$ \\
\hline GGGT(GGGGT) $)_{2} \mathrm{G}$ & 54 & 6 & 4 & $350-900$ \\
\hline
\end{tabular}

The products of the amplifications were separated on $2.0 \%$ agarose gel along with the 1-kb marker DNA Ladder (Invitrogen). The gel was stained with a mixture of Blue Juice and GelRed (as above, in the DNA extraction).

\section{Data analysis}

For the analysis of ISSR markers, the gels were interpreted by the presence and absence of bands, generating a binary matrix. The complement of the Jaccard similarity coefficient was used to estimate the genetic distances between the genotypes. The genetic distances were analyzed using UPGMA (unweighted pair-group method using arithmetic average). The variability between and within the populations Cimmyt and Piranão was also evaluated by molecular variance analysis (MANOVA). All the analyses were carried out using R (http:// www.r-project.org) and GENES (Cruz, 2006) software systems.

\section{RESULTS AND DISCUSSION}

In the ISSR analysis, each primer produced easily detected bands of variable intensity; nonspecific bands were discarded. The 13 primers produced 140 bands (Table 1). Of these, $81.4 \%$ were polymorphic and $18.6 \%$ monomorphic. Progenies 1 and 81 were the most distant (0.6883), while 49 and 50 were the most similar (0.3846). This result was expected, since the progenies 1 and 81 belong to the populations Cimmyt and Piranão, respectively, while progenies 49 and 50 both belong to Piranão.

Using the cutoff point distance of 0.51 , the most abrupt decision point in the dendrogram, two large groups were formed, these being the populations Cimmyt and Piranão (Figure 2). There was demonstrable variability between and within the populations. Based on these groupings, it is possible to infer that gains per se can be achieved by means of selection, and that heterosis maximization is expected in inter-population crossings. These results are similar to those of Tardin et al. (2007), who evaluated genetic divergence between families of full siblings of the same populations at the eighth cycle of reciprocal recurrent selection. 


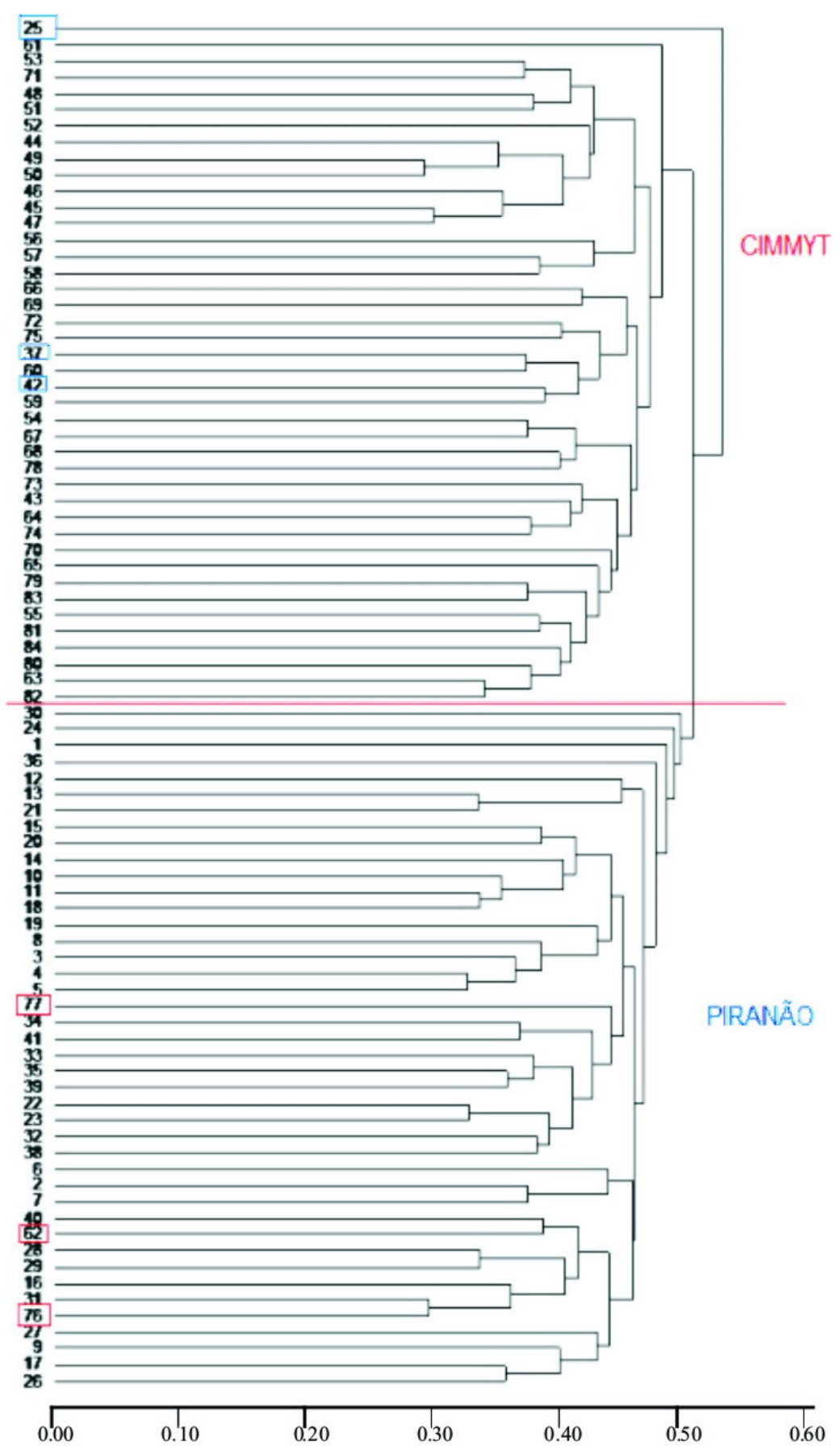

Figure 2. Dendrogram of the $84 \mathrm{~S}_{1}$ genotypes produced by the UPGMA method; genotypes 1 to 41 belong to the group Piranão and genotypes 42 to 84 , to the group Cimmyt. 
The UPGMA grouping analysis (Figure 2) allowed identification of "contaminant" progenies, here defined as progenies that belong to the groups Piranão or Cimmyt, but cluster in the opposite heterotic group. By projecting the distance on the plane (Figure 3), these and other progenies were also allocated intermediately between the two populations in the twodimensional plane. The identification of "contaminant" and intermediate progenies is relevant in selection, since they reliably identify the genotypes that should be eliminated from the recombination stage, which is vital when heterosis utilization maximization is desirable. It also assures maintenance of the genetic distance between the populations, and therefore longevity of the recurrent selection program.

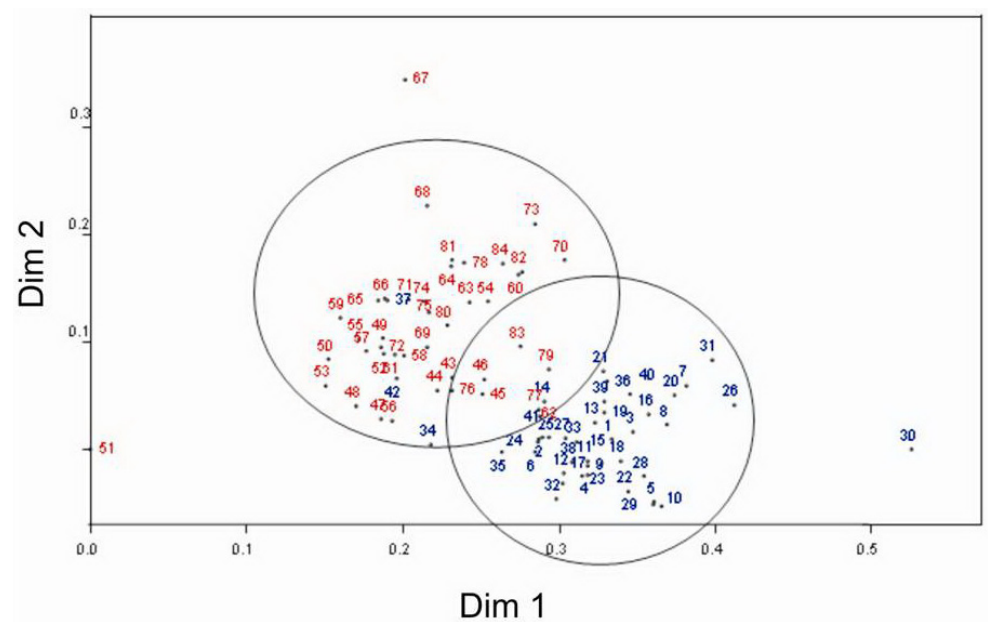

Figure 3. Dispersion graph of the 84 families genotyped using inter-simple sequence repeats. Genotypes in blue belong to the population Piranão and in red, to the population Cimmyt.

These "contaminants" could be due to i) mixture of seeds of the two populations; ii) cross-pollination between the populations or iii) overlapping of accesses, characterized by descendants with similar characteristics located in the intersection area of the two sets, since even coming from populations of different heterotic groups, the progenies have genetic similarities.

Each recurrent selection cycle basically involves three stages: i) development of progenies; ii) evaluation and selection of the progenies, and iii) recombination of the superior progenies. Considering this fact, the progenies that are selected and recombined must be sufficiently divergent to enable the recombination process to reestablish the genetic variability and ensure the continuity of the following cycles. In this context, inclusion of molecular markers allows us to reliably identify the maximum genetic variability within the groups, thus allowing increased intergroup distance. Based on this premise, the "contaminant" and intermediate progenies between the populations Cimmyt and Piranão were eliminated in order to maximize variability between them (Figure 4).

Comparison between Figures 3 and 4 leads to the conclusion that the molecular markers employed at the selection stage contributed to increase the genetic distance between the two populations, because of the elimination of the "contaminant" genotypes. These populations are at the 10th reciprocal recurrent selection cycle; since at the 
eighth cycle, selection has been monitored with molecular markers, using RAPDs at the eighth selection cycle (Tardin et al., 2007) and AFLPs, at the ninth cycle (Gabriel, 2006).

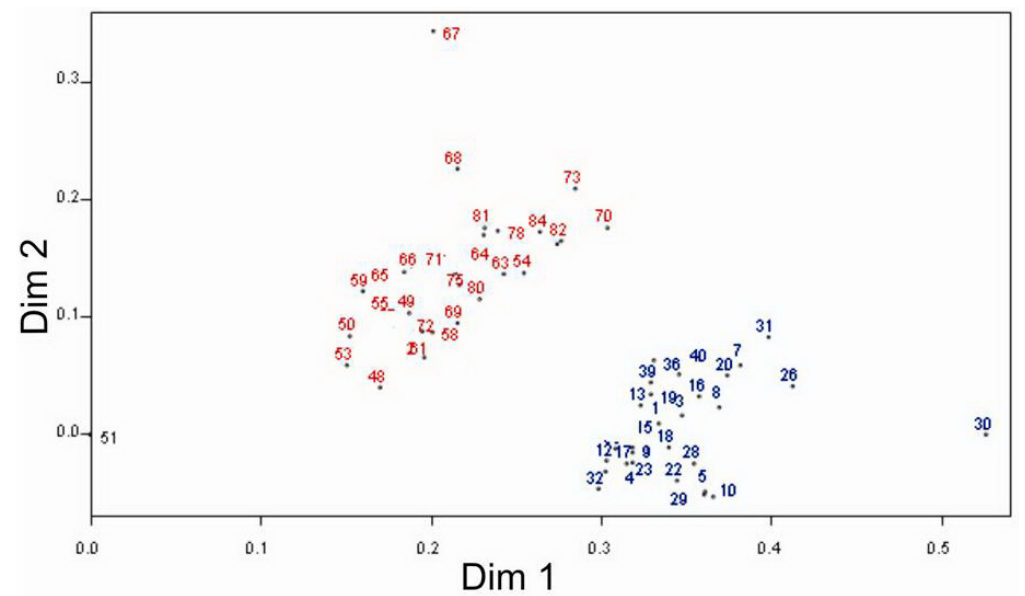

Figure 4. Dispersion graph of the 50 families selected for the recombination stage. Genotypes in blue belong to the population Piranão and in red, to the population Cimmyt.

AMOVA of the $84 \mathrm{~S}$ progenies of the populations Cimmyt and Piranão revealed that most genetic variation, $89.8 \%$, occurs within populations (Table 2). After the elimination of the contaminant progenies and the selection of the most distant progenies, the genetic divergence between the populations increased to $14.3 \%$. These genetic distance values indicate that application of molecular markers for selection of superior genotypes can help increase genetic distance between populations, which allows us to maximize heterosis, besides increasing longevity of the reciprocal recurrent program.

Table 2. Analysis of molecular variance of the maize populations Cimmyt and Piranão before and after molecular
genotyping.
\begin{tabular}{lccccc}
\hline Before genotyping \\
\hline Source of variation & d.f. & MS & Variance components & Percentage & Probability \\
\hline Among populations & 1 & 175.7994 & 3.4592 & 10.1578 & $<0.001$ \\
Within populations & 82 & 30.5954 & 30.5954 & 89.8422 & $<0.001$ \\
Total & 83 & 32.3448 & 34.0546 & 100 & $<0.001$ \\
\hline After genotyping & & & & & \\
\hline Source of variation & d.f. & MS & Variance components & Percentage & Probability \\
\hline Among populations & 1 & 155.94 & 5.0293 & 14.27 & $<0.001$ \\
Within populations & 48 & 30.2067 & 30.2067 & 85.72 & $<0.001$ \\
Total & 49 & 32.7727 & 35.236 & 100 & $<0.001$ \\
\hline
\end{tabular}

d.f. $=$ degrees of freedom; MS $=$ mean squares of traits.

\section{REFERENCES}

Agarwal M, Shrivastava N and Padh H (2008). Advances in molecular marker techniques and their applications in plant sciences. Plant Cell Rep. 27: 617-631. 
Buckler ES, Gaut BS and McMullen MD (2006). Molecular and functional diversity of maize. Curr. Opin. Plant Biol. 9: 172-176.

Collard BC and Mackill DJ (2008). Marker-assisted selection: an approach for precision plant breeding in the twenty-first century. Philos. Trans. R. Soc. Lond B Biol. Sci. 363: 557-572.

Comstock RE and Robinson HF (1948). The components of genetic variance in populations of biparental progenies and their use in estimating the average degree of dominance. Biometrics 4: 254-266.

Cruz CD (2006). GENES Software: Version Windows: Computerapplication in Genetics and Statistics. Federal University of Viçosa, Viçosa.

Daher RF, Pereira MG, Pereira AV and do Amaral Júnior AT (2002). Genetic divergence among Elephantgrass cultivars assessed by RAPD markers in composit samples. Sci. Agric. 59: 623-627.

Doyle JJ and Doyle JL (1990). Isolation of plant DNA from fresh tissue. Focus 12: 13-15.

Gabriel APC (2006). Seleção Recorrente Recíproca em Famílias de Irmãos Completos em Milho (Zea mays L.) Assistida por Marcadores Moleculares. Master's thesis, UENF, Campos dos Goytacazes.

Gabriel APC (2009). Seleção Recorrente Recíproca de Famílias de Irmãos Completos em Milho Comum (Zea mays L.) Monitorada por Marcadores Moleculares: Avanço de Gerações e Avaliação de Progresso Genético. Master's thesis,UENF, Campos dos Goytacazes.

Gonçalves LS, Rodrigues R, Amaral AT Jr, Karasawa M, et al. (2008). Comparison of multivariate statistical algorithms to cluster tomato heirloom accessions. Genet. Mol. Res. 7: 1289-1297.

Hallauer AR and Miranda Filho JB (1988). Quantitative in Maize Breeding. 2nd edn. Iowa State University Press, Ames.

Leal AA, Mangolin CA, do Amaral ATJ, Goncalves LS, et al. (2010). Efficiency of RAPD versus SSR markers for determining genetic diversity among popcorn lines. Genet. Mol. Res. 9: 9-18.

Lima Neto FP and Souza Júnior CL (2009). Number of recombinations and genetic properties of a maize population undergoing recurrent selection. Sci. Agric. 66: 52-58.

Mohammadi SA and Prasanna BM (2003). Analysis of genetic diversity in crop plants - salient statistical tools and considerations. Crop Sci. 43: 1235-1248.

Moose SP and Mumm RH (2008). Molecular plant breeding as the foundation for 21st century crop improvement. Plant Physiol. 147: 969-977.

Pinto LR, Vieira MLC, Souza CL and Souza AP (2003a). Genetic-diversity assessed by microsatellites in tropical maize populations submitted to a high-intensity reciprocal recurrent selection. Euphytica 134: 277-286.

Pinto LR, Vieira MLC, Souza CL and Souza AP (2003b). Reciprocal recurrent selection effects on the genetic structure of tropical maize populations assessed at microsatellite loci. Genet. Mol. Biol. 26: 355-364.

Reif JC, Melchinger AE and Frisch M (2005). Genetical and mathematical properties of similarity and dissimilarity coefficients applied in plant breeding and seed bank management. Crop Sci. 45: 1-7.

Tardin FD, Pereira MG, Gabriel APC, do Amaral Júnior AT, et al. (2007). Selection index and molecular markers in reciprocal recurrent selection in maize. Crop Breed. Appl. Biotechnol. 7: 225-233.

Williams JG, Kubelik AR, Livak KJ, Rafalski JA, et al. (1990). DNA polymorphisms amplified by arbitrary primers are useful as genetic markers. Nucleic Acids Res. 18: 6531-6535. 